\title{
COUNTRY REPORT ON JORDAN: ADVANCING ICT LEADERSHIP ACROSS MENA
}

Omar J. Khan, Morgan State University, Baltimore, Maryland, U.S.A.

\author{
dx.doi.org/10.18374/JIBE-20-1.3
}

\begin{abstract}
This paper presents a country report, based on extensive qualitative research interviews, about Jordan and how its ICT (Information and Communication Technologies) sector has become a leader within the MENA region. The paper ties in key elements of the regionalization, nation branding and knowledge literature, in order to elucidate the strengths, weaknesses, opportunities and threats that the country's ICT sector has faced and leveraged. It provides key insights into how other emerging markets can engage in successful international business development using Jordan's example.
\end{abstract}

Keywords: Jordan, emerging markets, regionalization, nation branding 